\title{
Production of Dietetic Bakery Product - Tapa-Nan with Functional Additives
}

\author{
Anvarbek Yusupovich Beisenbayev ${ }^{1}$, Zhumakhan Ushkempirovich Myrkhalykov ${ }^{1}$, Marat Isakovich Satayev ${ }^{1}$, \\ Zarina Anvarbekovna Beisenbaeva ${ }^{1}$, Dekkhangul Dzhandarbekova ${ }^{1} \&$ Gulzhan Orynbasarovna Kantureyeva ${ }^{1}$ \\ ${ }^{1}$ M. Auezov South Kazakhstan State University, Republic of Kazakhstan
}

Correspondence: Anvarbek Yusupovich Beisenbayev, M. Auezov South Kazakhstan State University, Shymkent city, Tauke khan, 5, Republic of Kazakhstan.

Received: December 6, 2014

doi:10.5539/mas.v9n9p259
Accepted: January 19, $2015 \quad$ Online Published: August 30, 2015

URL: http://dx.doi.org/10.5539/mas.v9n9p259

\begin{abstract}
In this study $12 \%$ mixture of mashed carrot and pumpkin and powder of pumpkin seeds and medicinal herbs: St.-John's-wort (Hypericum L); thousand-leaf (Achilea millefolium L.) and licorice root (xty.beat) were used to enrich dietetic bakery product - tapa-nan produced with first grade wheat flour.

The effect of addition on dough on its rheological properties, on bread on its physical-chemical and sensory parameters of bread was studied. The results showed that the baking properties of flour and the rheological properties of the dough with additives at a dosage $12 \%$ to weight fraction of flour increased significantly $(p<0.05)$. It was found that the introduction of mixture has intensifying effect on the fermentation process, reduces gluten content and strengthens its structural and mechanical properties. Also the reduction of the dough fermentation period and expenses of dried substances were found. Introduction of functional additives increased the water absorption capacity of flour (WAC), lowered dilution of dough consistency; as well its elasticity improved.

Physical - chemical parameters of the proposed dietetic national bakery product (tapa-nan) such as moisture, porosity, titratable acidity showed no significantly $(\mathrm{p}<0.05)$ different. In appearances, taste, smell and flavor definitions showed that addition of $12 \%$ mixture of mashed carrot and pumpkin and powder of pumpkin seeds and medicinal herbs: St.-John's-wort (Hypericum L); thousand-leaf (Achilea millefolium L.) and licorice root (xty.beat) had more to yellowness. In texture characteristics, the result showed the hardness of bread decreased and chew ability improved. Apart from that, biological value of enriched bread increased.
\end{abstract}

Keywords: bread, dietetic, dietary fiber, medicinal herbs, melon crops, tapa-nan

\section{Introduction}

It is recognized that dietary food with adequate contents of functional constituents may reduce the risk of cardiovascular diseases, diabetes, cancer, obesity, severe gastrointestinal disease, etc. Understanding the role of various bioactive food components of vegetable origin in human health and disease prevention gives a boost to development of innumerable everyday foods which have beneficial effects.

Nowadays consumers know more of what they eat, so fortification of necessaries of life, one of which is bread, with different natural biologically valuable and ecologically safe products became increasingly popular all over the world. Furthermore, the bread can be part of a healthy dietetic nutrition focused on disease prevention as long as it is enriched with items like medicinal herbs and vegetables products. The healthy effect of fortifiers is mainly referred to the dietary fiber and micronutrients.

Thus, expanding the range of dietary bakery goods of therapeutic and prophylactic designation can be solved by raising the nutritive value of foods by the addition of functional components. Analysis of published data, scientific journals, various sources of patent development shows (Franco, 2009; Krasina, 2004; Kretovich, 2002; KZ innovative patent A4 No. 26009, 2012; Robertson et al., 2003; RU patent C1 No. 156575, 2000; RU patent C1 No. 2439995, 2012; Smertina, 2011; Sokol, 2006; Yessaulko, 2011) that the use of unconventional materials and various kinds of additives (medicinal herbs and melon crops) in the production of new kinds of healthy food of therapeutic and preventive purposes is a promising and cost-effective.

Yessaulko (2011), in his study had discussed the possibility of replacing sugar with aqueous extract of stevia in 
the functional bakery production for diabetics and people of risk group. Based on the analysis of the studies results stevia leaves can be taken as a biologically active plant, sugar replacing component in the development of the compositions of bread. There is evidence that the product of processing of stevia - stevioside - has a bleaching effect on the crumb of bread and bakery products have curative properties and extended shelf life.

From this point of view, the perspective creates special purpose breads having therapeutic or preventive properties due to the introduction of the functional additives in the formulation. High nutritional value and curative possibilities of such functional additives provide creation of a wide range of food products of new generation, which meet modern requirements (Kretovich, 2002; Marmuzova, 2008; Perfilova, 2010). These functional products can be gotten from a wide variety of vegetable raw materials with balanced composition, which provide phytochemicals that may be used in food systems (Smertina, 2011; Sokol, 2006).

Epidemiological evidence has shown that a diet containing not enough dietary fiber can result in numerous human diseases. Dietary fiber contains in cereals, fruits, vegetables; it can be also produced from waste products.

As for using powders and feeds of medicinal plants from separate plants for production of everyday food, researches in this field have not produced positive results because persistent smell of herbs is not compatible with the products. However, Prajapati, N.D., et al.(2003), Srinivasan K (2005) suggested using powders of medicinal herbs in the mixture for these purposes.

Some scientific studies (Smertina, 2011) have demonstrated the use of hydrobionts of plant origin as brown algae Costaria costata, in the technology of bakery products. There were shown influence of the introduced algae on the quality of the main raw materials, the effect of Costaria costata on staling process, as well commodity evaluation of developed bread with the specified functional properties.

The increasing of the palatability of melons crops and studying their medicinal properties has become a new research in scientific papers (Franco, 2009). With melons, aimed at increasing the fruits of biologically active substances (pectin, carotene, vitamin $\mathrm{C}$, sugars, folic acid), which are not inferior to treatment and valuable properties to foreign analogues varieties and hybrids. This allows more efficient use of them for the prevention and treatment of specific diseases (Lymar et al., 2003).

Production of these crops (watermelon, melon, pumpkin) can be used both in the natural and in the form of processed products (Shaprov, 2008). If the watermelon and melon are generally used only in its natural form, the pumpkin allows extending the applicability due to more storage time. Very promising is using processing products of pumpkin in the bread technology (Atayev, 2009). Pumpkin is a good source of carotenoids which is one of the phytochemicals reducing the developing some degenerative diseases, and providing the attractive colour of many fruits and vegetables. Pumpkin is rich in fiber, vitamins B6, B1 and B2, K, ascorbic acid, niacin, as well as minerals like potassium, phosphorus, magnesium, iron and selenium (USDA National Nutrient Database, 2004). Pumpkin pulp and juice improve function in constipation, increase the excretion of chlorides from the body, increase dieresis, without causing irritating effects on renal tissue. It is prescribed for liver diseases, kidney, and gout. Taking into account promising application of pumpkin, especially from the perspective of biomedical, microbial fermented substrates ways to use it in the bread technology were developed (Skripnikov, 2009).

The proposed formulation (KZ innovative patent A4 No. 26009, 2012) of bread production of increased biological value with curative properties, provides getting a probiotic bio bread enriched with enzymes, vitamin $\mathrm{C}, \beta$-carotene, folic acid, live lactic acid bacteria, allowing be attributed to probiotic product that provides improved biocenosis of the gastrointestinal tract and increased immunity to diseases such as anemia, goiter, cancer. The results described in the work (RU patent C1 No. 156575, 2000), give grounds to conclude that the biologically active food supplements on the basis of hydro-alcoholic extracts obtained from processing waste of viburnum, Chinese magnolia vine and Amur grape, can be used as functional ingredients in the manufacture of medical and bakery products of preventive appointment, thereby increasing the nutritional value of the finished product and improving its quality.

The result of the proposed formulation (RU patent C1 No. 2439995, 2012) is to improve the product quality by improving their sensory characteristics, increasing the biological value of products, the intensification of the fermentation process, the reduction in expenses of dry substances during fermentation, increase yield and reduce the products cost. The proposed recipe for making bread "Filippok" allows to: obtain a functional product for the prevention and treatment of gastrointestinal, cardiovascular disease, atherosclerosis, for the prophylactic treatment of patients with diabetes; improve product bioavailability by $5 \%$; improve it sensory and physical and chemical quality; shorten the fermentation period for 60 minutes, by increasing the initial acidity of the dough, which is achieved by adding daikon and pumpkin puree in a ratio of $1: 1$; to reduce costs of dry substances for 
fermentation by $1.5 \%$; increase the yield of products by $5.8 \%$; lower the cost.

Also it has been reported that mashed carrot and pumpkin which are rich in digestible sugars - fructose, glucose, were well consumed by yeast cells, as well contents of protein substances (6.5\% to DS), among which are necessary for vital activity of yeast cells amino acids, provided good fermentation of dough (Franco, 2009). From the minerals necessary for life activity of yeast, mashed carrots and pumpkin contain nitrogen, phosphorus, and magnesium, iron and copper. It is known that dried pumpkin seeds, leaves and roots of herbs: St.-John's-wort (Hypericum L); thousand-leaf (Achilea millefolium L.) and licorice root (xty.beat) have high content of dietary fibers, oligosaccharides, bioflavonoids, water-soluble vitamins, macro- and microelements. In this context, a given study has shown the method of preparation of novel national bread with adding functional components.

The objective of this research was to develop formulation of dietary, national bakery product (tapa-nan) of medical and preventive appointment with improved nutritional and biological value, with good sensory and physical and chemical characteristics. The effect of fortification of bread with functional components on dough composition and its rheological properties, as well on quality parameters of ready baked product such as contents of crude gluten of dough, its fermentation time and color, flavor, humidity and acidity of bread were defined and compared with bread produced without suggested additives.

\section{Materials and methods}

\subsection{Functional Additives Samples}

Investigations were carried out at laboratory of the chair Food Engineering and test regional laboratory of engineering profile of M.Auezov South Kazakhstan State University (Shymkent).

As functional additives semi-finished products prepared from local plant raw materials and medicinal herbs growing and harvested in South region of Kazakhstan were used. Food samples of carrot and pumpkin were obtained from a local market in September-October of 2013. Medicinal herbs as St.-John's-wort (Hypericum L); thousand-leaf (Achilea millefolium L.) and licorice root (xty.beat) were purchased in local compounding pharmacy.

For enriching products with functional additives dough from first grade wheat flour and other necessary components were used. The composition of ingredients for preparing the fermented dough included 1-st grade wheat flour, sugar, salt, yeast and tap water.

Carrot samples were soaked, handled with steam for 15-20 min and purified. Samples of pumpkin were washed, purified and cut. Prepared pieces of vegetables were blanched and forced through a sieve with a mesh diameter of not more than $0.4 \mathrm{~mm}$. Samples of mashed carrot and pumpkin were mixed in a weight ratio $-1: 1(\mathrm{w} / \mathrm{w})$. The mix was then boiled at a temperature of $100{ }^{\circ} \mathrm{C}$ to a solids content of $10-12 \%$ and $\mathrm{pH}=6,5-7,5$. Gotten puree was cooled and stored in a refrigerated chamber at $0{ }^{\circ} \mathrm{C}$ until use.

Seeds of pumpkin were dehydrated to a moisture content of $6.5 \%$ and then grinded to reach size of particles 1,5-2,0 mm. Medicinal herbs as St.-John's-wort (Hypericum L); thousand-leaf (Achilea millefolium L.) and licorice root (xty.beat) were finely powdered to ensure homogeneous distribution in flour.

\subsection{Preparation of Functional Additives Blend}

Mixture of finely powdered medicinal herbs as St.-John's-wort (Hypericum L); thousand-leaf (Achilea millefolium L.) and licorice root (xty.beat) has been taken in equal proportions and blended with finely grinded seeds of pumpkin in a weight ratio - 1:1 (w/w) to get homogeneous mix. Mixture of pumpkin seeds, leaves and roots of medicinal plants: St.-John's-wort (Hypericum L); thousand-leaf (Achilea millefolium L.) and licorice root (xty.beat) then were thoroughly mixed with carrot and pumpkin puree in a weight ratio $-1: 1(\mathrm{w} / \mathrm{w})$.

\subsection{Bread Preparation}

Wheat flour of first grade was mixed with previously blended mix of functional additives at $15 \%(\mathrm{w} / \mathrm{w})$ level, and then bakery yeast, common salt, sugar and water were added. Further widespread in dough processing methods were used: fermentation, shaping dough, baking and cooling.

The duration of fermentation dough is $110 \mathrm{~min}$ to a final acidity of 3 degrees. Further dough pieces were formed and molded, then proofed during $40-50 \mathrm{~min}$ at $35-40{ }^{\circ} \mathrm{C}$ and air relative humidity $75-80 \%$ and finely baked 11-14 minutes at $220-230^{\circ} \mathrm{C}$, then cooled. The method is illustrated by the following examples:

\subsection{Preparation of Sample Bread}

The dough was kneaded by straight method from $100 \mathrm{~g}$ of first grade bakery wheat flour, $3 \mathrm{~g}$ of bakery yeast, 1.0 $\mathrm{g}$ of sugar, $1.3 \mathrm{~g}$ of common salt and water. The dough was fermented for 180 minutes; the dough pieces are 
formed and molded, further proofed for 50 minutes at $40{ }^{\circ} \mathrm{C}$ and a relative humidity of $80 \%$ for 14 minutes and baked at $230{ }^{\circ} \mathrm{C}$, then cooled. Expenses of dry matters for fermentation were 3.5\%, the yield of products was equal to $132.1 \%$.

\subsection{Preparation of Experimental Bread}

The dough was kneaded by straight method from $100 \mathrm{~g}$ of first grade bakery wheat flour, $12 \mathrm{~g}$ of thoroughly mixed blend of pumpkin seeds, leaves and roots of medicinal plants: St.-John's-wort (Hypericum L); thousand-leaf (Achilea millefolium L.) and licorice root (xty.beat) with carrot and pumpkin puree, $3 \mathrm{~g}$ of bakery yeast, $1.0 \mathrm{~g}$ of sugar, $1.3 \mathrm{~g}$ of common salt and water. The dough was fermented for 110 minutes; the dough pieces were formed and molded, further proofed for 40 minutes at $40{ }^{\circ} \mathrm{C}$ and a relative humidity of $80 \%$ for 11 minutes and baked at $220{ }^{\circ} \mathrm{C}$, then cooled. Expenses of dry matters for fermentation were $2 \%$, the yield of products was equal to $135.7 \%$. The product acquired functional properties.

\section{Results and Discussion}

\subsection{Baking Properties of Flour and the Rheological Properties of the Dough}

The prior studies on functional additives consisting of pumpkin flesh and seeds and medicinal herbs to various kinds of bread revealed that dough composition and its rheological properties, as well on quality parameters of ready baked product such as contents of crude gluten of dough, its fermentation time and color, flavor, humidity and acidity of bread were not optimal for functional components addition more than $15 \%$ (RU patent C1 No. 2439995, 2012, Urazbayeva et al., 2013). Consequently, in this work $12 \%$ functional components addition was used for fortification of national bread tapa-nan.

To study the influence of mashed carrot and pumpkin and powder of pumpkin seeds and medicinal herbs: St.-John's-wort (Hypericum L); thousand-leaf (Achilea millefolium L.) and licorice root (xty.beat) on the baking properties of flour and the rheological properties of the dough additives were added at a dosage from 3 to $12 \%$ to weight fraction of flour. It was found that the introduction $12 \%$ of mixture has intensifying effect on the fermentation process - there is an increase of acidity test and increase gas production in the dough due to an increase in the medium easily fermentable carbohydrates, which are additional food for microorganisms. Adding to the flour mashed carrots and pumpkin and powder of pumpkin seeds and medicinal plants: St.-John's-wort (Hypericum L); thousand-leaf (Achilea millefolium L.) and licorice root (xty.beat) reduces gluten content and strengthen its structural and mechanical properties, as evidenced by reductions in deformation compared to the control (Figures 1,2).

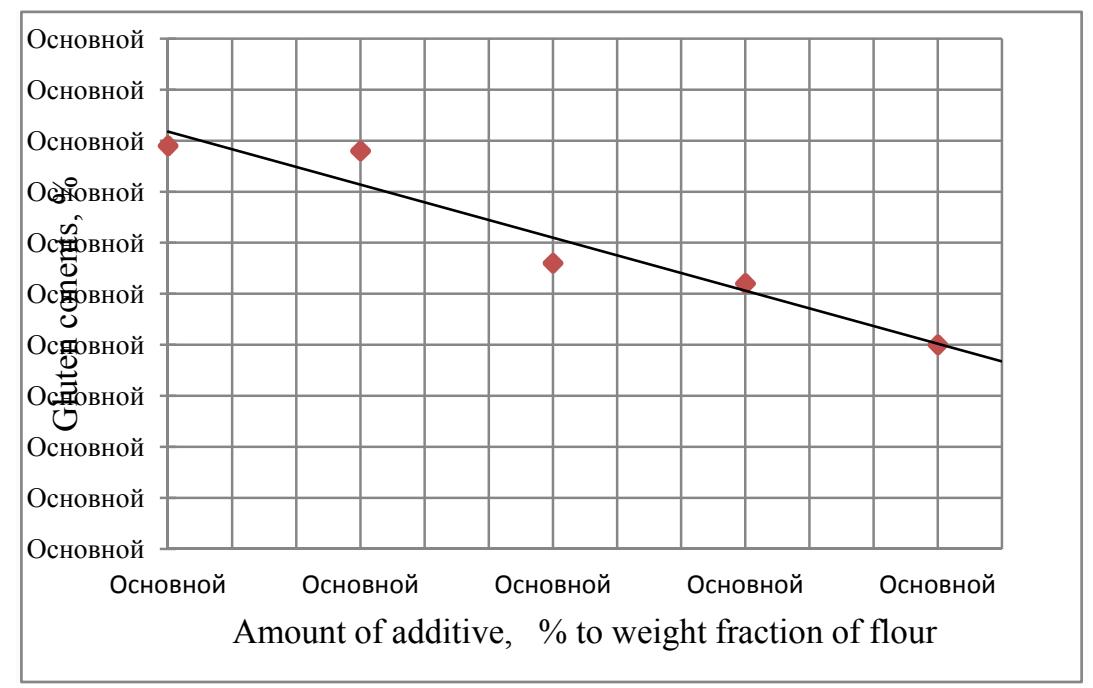

Figure 1. Effect of additive on gluten contents 


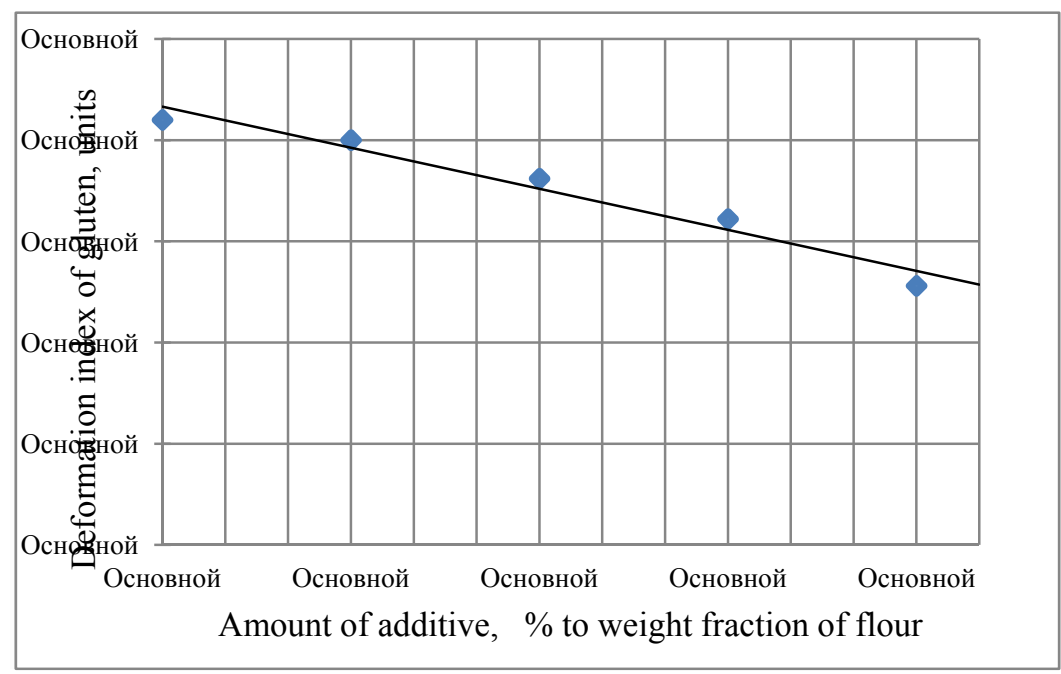

Figure 2. Effect of additive on deformation index of gluten

Increasing the elastic properties of gluten, is apparently a result of the formation of protein-polysaccharide complexes at interacting flour proteins with polysaccharides of additives, which leads to compaction of protein structures due to the additional formation of new bonds (ionic, hydrogen, hydrophobic interaction). Also polyphenolic compounds, ascorbic acid, peroxides produced from lipids unsaturated FA of pumpkin seeds powders, which have an inhibitory effect on the proteolytic enzymes of flour and the reinforcing intermolecular structure of the protein, may contribute to the gluten strengthening.

The reduction of the dough fermentation period and expenses of dried substances was because the fact that adding mixture of mashed carrot and pumpkin and powder of pumpkin seeds and medicinal herbs: St.-John's-wort (Hypericum L); thousand-leaf (Achilea millefolium L.) and licorice root (xty.beat) with initial acidity of dough equal to $\mathrm{pH} 5.05$ the last was increased from 2.2 to 2.8 degrees, so a given final acidity of dough 3.0 was achieved faster than that of the prototype on 70 minutes. That provided the removal of stress relaxation in the gluten framework of freshly kneaded dough. In this case gluten dough prepared by the proposed method acquired physical properties of gluten, corresponding to gluten dough of prototype, i.e. contraction amount of gluten after 110 minutes fermentation was 55.6 units by scale of IDK (deformation index of gluten) device; fermentation activity increased.

Introduction of functional additives increased the water absorption capacity of flour (WAC), lowered dilution of dough consistency; as well its elasticity improved compared with controls. The greatest change values of shown indicators were found in the samples with $12 \%$ of mixture of mashed carrot and pumpkin and powder of pumpkin seeds and medicinal herbs: St.-John's-wort (Hypericum L); thousand-leaf (Achilea millefolium L.) and licorice root (xty.beat) (Figures 3,4). 


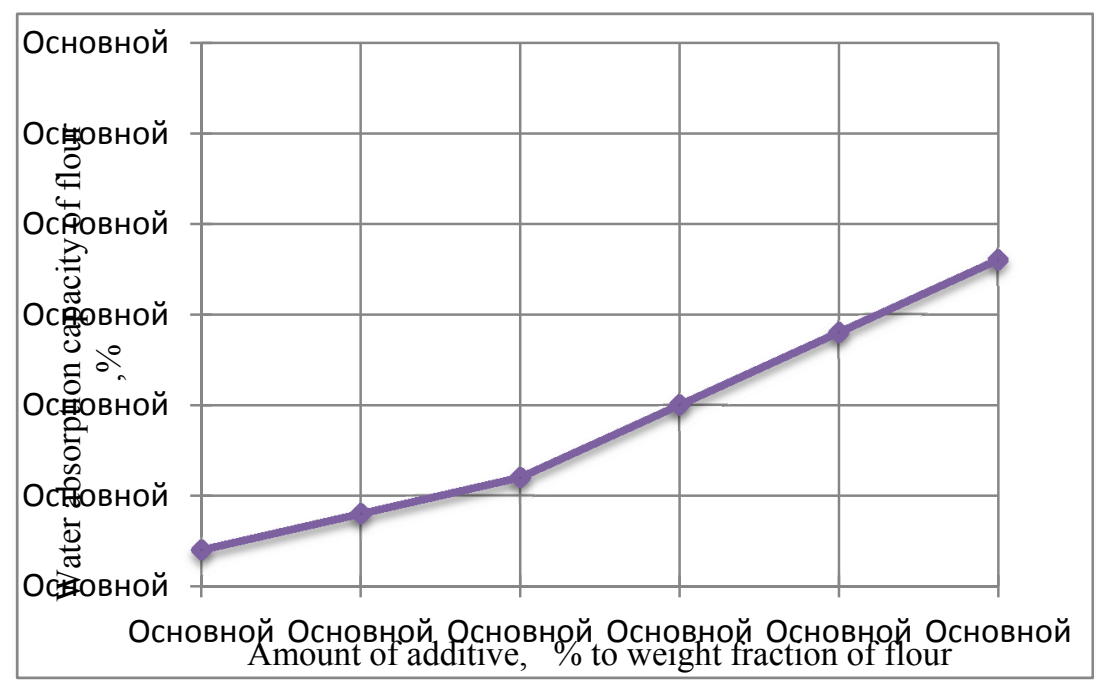

Figure 3. Effect of additive on WAC of flour

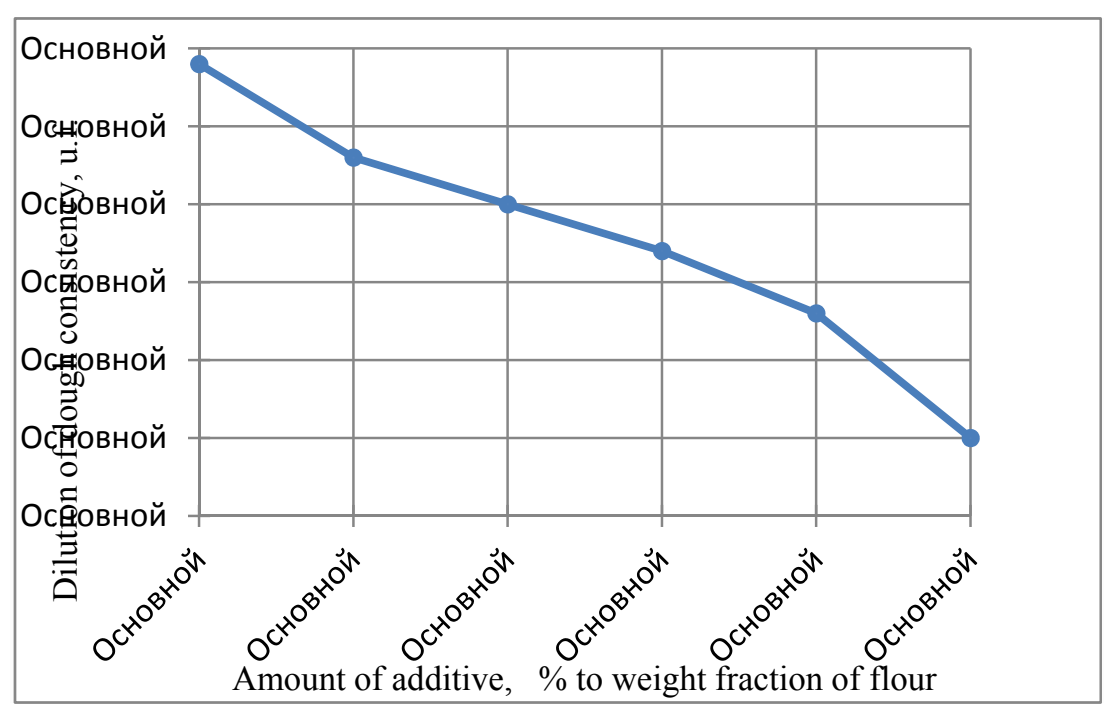

Figure 4. Effect of additive on dilution of dough consistency

\subsection{Sensory and Physical and Chemical Estimation of Enriched Bread}

Table 1 shows the results of sensory and physical and chemical estimation of enriched with $12 \%$ of mixture of mashed carrot and pumpkin and powder of pumpkin seeds and medicinal herbs: St.-John's-wort (Hypericum L); thousand-leaf (Achilea millefolium L.) and licorice root (xty.beat) bread.

Table 1. Sensory and physical - chemical estimation of enriched bread

\begin{tabular}{|c|c|}
\hline Parameter & Characteristics of product \\
\hline Form & Corresponding to bread baking dish, without side spew \\
\hline Surface & Without large cracks and explosions \\
\hline Color & Light yellow gold \\
\hline d smell & $\begin{array}{l}\text { Taste natural typical to this product type, without foreign taste; sweet, with the expressed } \\
\text { pleasant taste of the carrot and pumpkin and slight tinge of herbs. The smell of the nature of } \\
\text { this product type more expressed, with characteristic pleasant aroma of carrot and pumpkin }\end{array}$ \\
\hline Degree of baking & $\begin{array}{l}\text { Well baked, not wet to the touch, elastic, after a light finger pressure crumb takes its original } \\
\text { shape }\end{array}$ \\
\hline Degree & Without lumps and traces of weak kneading \\
\hline
\end{tabular}




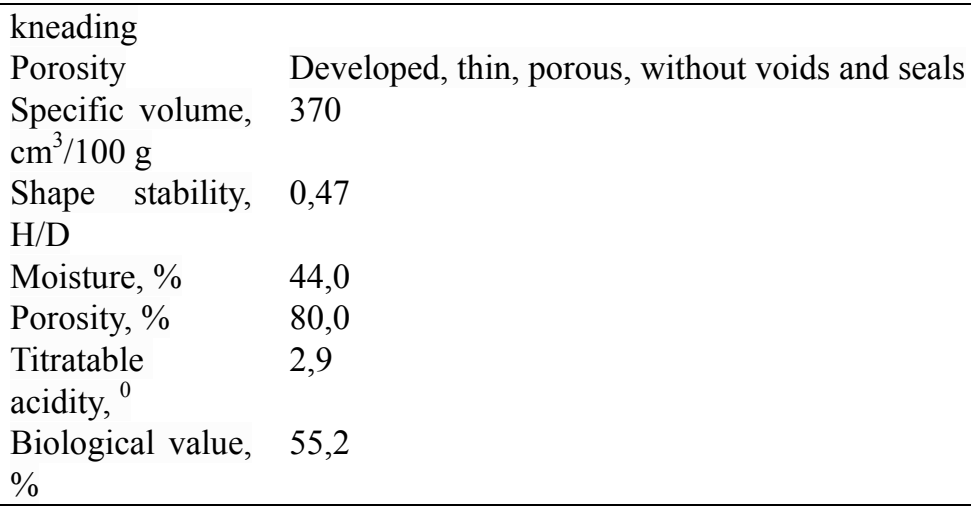

The appearances, taste, smell and flavor are undoubtedly the most important attributes determining the quality of bread or baked cereals in general and one of the most important attributes influencing the acceptance of the consumer (Hansen, Schieberle, 2005). The proposed dietetic national bakery product (tapa-nan) was corresponding to the shape of the flat breads. The color of the proposed dietetic national bakery product (tapa-nan) were better than color of control bread, might be due to the addition of carrot and pumpkin, which have specific yellow color. The results of the present study are in agree with the findings of Urazbayeva et al., 2013) who show a decrease in the color saturation of bread with the addition of pumpkin powder.

Bread flavor is a key element for consumer acceptance and product identification (Salim-ur-Rehman et al.,2006). The flavors of the proposed dietetic national bakery product (tapa-nan) were more pleasant than that of control breads, which suggested that the addition of vegetables and herbs improved the bread's flavor. The improvement in the flavor of the suggested bread might be due to the production of acids and volatile compounds during fermentation and baking bread with additives, resulting in stronger flavor of proposed bread.

The chewability is related to degree of baking and kneading, and porosity of the bread (Zobel H. F. and Kulp K. 1996). The study showed that proposed dietetic national bakery product (tapa-nan) had less hardness and more chewability, compared to control. It might be due to the high presence of dietary fibers in bread, which was less sticky compared to control.

Physical - chemical parameters of the proposed dietetic national bakery product (tapa-nan) were in accordance with requirements of flat bread quality (ISIRI., 2002, Chizhova, K.N., 2005).

\section{Conclusion}

The proposed method of production of dietetic bakery product - tapa-nan with functional additives as $12 \%$ of mixture of mashed carrot and pumpkin and powder of pumpkin seeds and medicinal herbs: St.-John's-wort (Hypericum L); thousand-leaf (Achilea millefolium L.) and licorice root (xty.beat) resulted in functional product for the prevention and treatment of gastrointestinal, cardiovascular diseases, atherosclerosis in the prophylactic treatment of patients with diabetes; increased the biological value of the products to 7\%; improved sensory and physical-chemical quality indicators; reduced the period of dough fermentation to 60 minutes, by increasing the initial dough acidity; reduced the expenses of solids on the fermentation of $1.5 \%$; increased output of products to $5.8 \%$.

Therefore mixture of mashed carrot and pumpkin and powder of pumpkin seeds and medicinal herbs: St.-John's-wort (Hypericum L); thousand-leaf (Achilea millefolium L.) and licorice root (xty.beat) could be regarded as potential health-promoting functional ingredient.

\section{References}

Atayev, A. A. (2009). Dietetic bakery products for healthy nutrition. Bread Baking of Russia, 4, p. 30).

Beisenbayev, A. Yu. (2013). Preparation method of national dietetic bread product, cake (tapa-nan) for dietetic nutrition" patent. M. Auezov SKSU, Shymkent city.

Chizhova, K. N. (2005). Technical control of bread production. M.: “Academy” (482 p.)

Franco, Ye. P. (2009). Melon-seed, pumpkin and date honey. Journal of Functional Food, Krasnodar, 5, 123-125.

Franco, Ye. P. (2009). Use of plant raw materials for functional nutrition. Materials of International scientific-practical conference "Functional food", Krasnodar, 173-175. 
Hansen, S. (2005). Generation of aroma compounds during sour dough fermentation: Applied and fundamental aspects. Trends Food Sci. Technol., 16, 85-94.

ISIRI. (2002). Institute of standards and industrial research of Iran, number 5810. Flat bread: Lavash (in Persian)

Krasina, I. B. (2004). Technologies and products of healthy nutrition. Modern natural science advances, 9 , $45-48$.

Kretovich, V. L. (2002). Use of plant protein enriching agents in production of dietetic and medical products. Survey information, M.: AgroNIITEIMMP(P. 82).

KZ innovative patent A4 No. 26009 (2012.14.09). Bulletin No. 9. Production method of high biological value bread with therapeutic properties.

Lymar, A. O. (2003). Methodological recommendations for production of ecologically pure, biologically valuable products of watermelon and pumpkin with a view to use them in rational and dietetic food / Lymar A.O., Grigorov, Yu. G., Podrushnyak, A.Ye. et al., Kiev (No. 24, p. 9).

Marmuzova, L. V. (2008). Technology of bread production. M.: “Academy” (288 p.).

Perfilova, O. V. (2010). A new kind of bread with sweat briar. Achievements of Science and Techniques of Agricultural Complex, 8, 15-17.

Prajapati, N. D., Purohit, S. S., Sharma, A., \& Kumar, T. (2003). A Handbook of Medicinal Plants. Agribios India, Jodhpur, India, 362-3.

Robertson, A. (2003). Food and health in Europe. Abstract. Under the editorship of A. Robertson, C. Tirabo, T. Lobetein et al. Copenhagen: European regional office of WHO (38 p., http://www.euro. who.int/document/e 78578r.pdf.).

RU patent C1 No. 156575 (2000.27.09). Production method of bread.

RU patent C1 No. 2439995 (2012.20.01). Production method of "Fillipok" bread.

Shaprov, M. N. (2008). Complex processing of cucurbits crop fruits. Bulletin of Agro-Industrial Engineering, 4(12), 25.

Skripnikov, Yu. G. (2009). Use of pumpkin for production of preserved foods. Works of VSAU, 2, 115-117.

Smertina, Ye. S. (2011). Application of extracts of wild plants in the bakery products of functional purpose. Bulletin of TSEU, 3, 129-133).

Smertina, Ye. S. (2011). Innovative approaches in use of phytogenic hydrobionts in the bread baking. Materials of the First International Congress "Environmental, food and medical safety of humanity", November 14-17, 2011: Part 2, Moscow: Plekhanov REU (pp. 120-123).

Sokol, N. V. (2006). Use of pectin substances in food production of therapeutic and preventive purposes. Scientific Journal of Kuban, 24(8), 43-46.

Srinivasan, K. (2005). Role of spices beyond food flavoring: Nutraceuticals with multiple health effects. Food Reviews International, 21, 167-188.

Urazbayeva, K. A. (2013). Farinaceous partly baked bread for preparation of dietetic baursaks. Patent. M. Auezov SKSU, Shymkent city.

USDA National Nutrient Database (2004). Retrieved from http://www.nal.usda.gov/fnic/foodcomp

Yessaulko, N. A. (2011). Use of stevia for improvement of quality and extension of storage life for bakery products. Bulletin of Stavropol agricultural complex (Russian IF - 0.6), 4(4), 8.

Zobel H. F., \& Kulp K. (1996). In E. Ronald, \& H. F. Hebeda (ed.), Baked Goods Freshness, staling mechanism. New York, Marcel Dekker.

\section{Copyrights}

Copyright for this article is retained by the author(s), with first publication rights granted to the journal.

This is an open-access article distributed under the terms and conditions of the Creative Commons Attribution license (http://creativecommons.org/licenses/by/3.0/). 